\section{Amplification factors to estimate wind erosion of piles of soil with different heights: Numerical simulation and structure-from- motion photogrammetry verification}

\author{
B. Liu, J. Qu, and D. Ning
}

\begin{abstract}
In this study, we propose amplification factors of single conical piles with different heights and sizes to describe wind erosion acceleration effects of piles compared to flat erodible surfaces. It is not difficult using traditional wind erosion models to estimate wind erosion of flat agricultural land or pastoral surfaces. However, in the current form these models cannot be used for elevated surfaces such as dunes or piles, which may lead to more serious dust emission and air pollution. A computational fluid dynamics simulation was used to refine a wind erosion estimation method of pile from the US Environmental Protection Agency (USEPA) by dividing the pile surface into multiple subareas with constant wind speed for each subarea and then obtaining ratios of pile erosion to the corresponding flat surface by calculating the total erosion rate of the pile and that of a flat surface with the same floor area. The ratios as amplification factors, $E_{\text {amp }}$, for six pile sizes (from 1 to $12 \mathrm{~m}$ ) and five wind speed scenarios covering most erosive daily wind speeds from 824 stations throughout China were analyzed and fitted to equations to enable consideration of other heights and wind speed conditions. The changing patterns of the factors were verified using experimental surveys of two plots via the structure-from-motion photogrammetry method, which generated high-resolution digital elevation maps and detected detailed erosion changes. The erosion from a stockpile surface was found to be 2.52 to 7.16 times that from a flat surface with the same floor area, and the influence of pile height on amplification factor could be expressed by a logarithmic equation. These factors can be easily applied to estimate pile erosion by multiplying them by wind erosion results for flat surfaces obtained from other indexes or models. The procedure described in this paper can be extended to consider amplification or reduction effects of dunes, hills, piles, pits, and gullies with different shapes or configurations in relation to wind erosion. Furthermore, the reliability of wind erosion estimation over complex surfaces can be improved to implement specific soil conservation practices.
\end{abstract}

Key words: computational fluid dynamics - Dunhuang — pile — structure-from-motion photogrammetry-wind erosion

\footnotetext{
Wind erosion produces suspended particles from erodible surfaces and causes air pollution, land degradation, and human health problems. The impact of wind erosion is significant in areas severely affected by poor air quality, such as northern China. The effects of terrain obstructions like dunes or piles on modifying wind speed and wind erosion have long been identified (Bagnold 1941; Stunder and Arya 1988; Sullivan and Ajwa 2011). Several models have been developed and improved to estimate wind erosion
} 2001; Hagen 2001; Tatarko et al. 2016; Wagner 2013; Zhang et al. 2017). However, there are no models capable of estimating wind erosion from elevated surfaces because they are not able to consider or simulate the diverging flow speed and direction near the elevated structure. A more precise modeling of wind erosion can be achieved if the effect of terrain elevation or surface exposure to wind speed and thus to wind erosion can be considered (Toraño et al. 2007; Wagner 2013).

Strong variability in the wind distribution and uptake force of the wind over a stockpile can be caused by the modification of a pile as an obstacle on the wind path. Therefore, piles with different shapes, heights, and configurations have varying, usually much higher, erosion or dust emission potentials compared to a flat surface (Badr and Harion 2007; Furieri et al. 2014; Toraño et al. 2007). Numerical simulations (usually computational fluid dynamics [CFD]) provide an excellent tool to test the effect of pile shape, configuration, and of any neighboring obstacles or piles on the redistribution of air flow pattern (Badr and Harion 2005, 2007; Diego et al. 2009; Farimani et al. 2011; Ferreira et al. 2011; Furieri et al. 2014; Toraño et al. 2007, 2009; Turpin and Harion 2009, 2010). Use of CFD methods provides many advantages over field studies and wind tunnel experiments, and CFD delivers high-resolution results, has the capability to resolve the complexity of wind flow, and has high flexibility (Badr and Harion 2007; Smyth 2016). The goal of the majority of erosion estimations adopting CFD methods is to refine the empirical emission factor $(E F)$ formulations proposed by the US Environmental Protection Agency (USEPA 1995). This is achieved by providing a finer wind speed distribution (dividing the surface into subareas with constant wind speed intervals considered as separate erosion sources) over the pile surface. CFD simulated wind distribution results for elevated surfaces can be parameterized into coefficients or factors, which can then be applied to erosion estimation results from wind erosion models or empirical equations to approximate the final wind erosion over an elevated surface.

Similar research on wind distribution over sand dunes or other landforms using wind tunnel and CFD simulations have been performed in two dimensions (2D) and 3D (Smyth 2016). The details in the flow field and the interaction between landforms were studied perhaps over a wider range (dune
Benli Liu is an associate professor and Jianjun Qu is a research professor at the Dunhuang Gobi Desert Ecological and Environmental Research Station, Northwest Institute of Eco-Environment and Resources, Chinese Academy of Sciences, Lanzhou, China. Duihu Ning is a senior engineer in the International Research and Training Center on Erosion and Sedimentation, Beijing, China. 
type, orientation, evaluation, etc.) compared to that of stockpile research, which shows the reliability of CFD methods in wind calculations (Jackson et al. 2013; Liu et al. 2011; Parsons et al. 2004; Wakes 2013; Zhang et al. 2012).Yet, none of these studies were related to quantitative estimation of emission rate over sandy surfaces. The gap between wind estimation and sand erosion amount can be attributed to the strong impact of external sediment sources, e.g., the majority of sands that travel over a dune may come from an upwind area instead of emission from the dune surface itself. However, this is not a problem for the piles in construction sites since they are usually isolated without external sediment sources.

The stockpiles at coal power stations, steelworks, and other construction or production industries exist as important fugitive dust emission and air pollution sources. Stockpiles come in various sizes depending on the involved industries, but their shapes can be similar since a dry material has a certain angle of repose. Previous studies have focused on flow conditions, geometry, or on configuration of piles, but few considered the size factor. The effect of wind is stronger on the top section of a high pile, which causes severe wind erosion, as the streamwise wind speed increases logarithmically with height in the turbulent boundary layer and air flow accelerates along the windward slope (Badr and Harion 2007; Dong et al. 2002; Liu et al. 2011).

The objectives of this study were to determine the relationship between pile height and wind erosion potential, and to provide amplification factors or formulas that can be conveniently used to estimate wind erosion from elevated surfaces. The factors or formulas contain the effect of pile size and wind variation over pile surface on dust emission. We focus on the event-level erosion and factor instead of a long-period (12 months or so) value as in the original USEPA equations, but the method to consider for long-period amplification effect is also suggested.

\section{Materials and Methods}

US Environmental Protection Agency Emission Factor. Wind speeds over various parts of a pile differ; therefore, the premise of USEPA EF for wind-generated particulate emission from piles involves dividing the elevated surface into subareas with constant surface wind velocity intervals using results from wind tunnel experiments, calculating the erosion potential from each subarea, and summing up the total erosion amount for the whole pile surface. Each interval may have several subareas. To estimate the total emission from one wind event after one disturbance, a simplified EF can be estimated using equation 1 (USEPA 1995):

$E F=\sum_{i=1}^{N} P_{i} S_{i}$,

where $N$ is the number of subareas, $P_{i}$ is the erosion potential corresponding to the $i$ th subarea $\left(\mathrm{g} \mathrm{m}^{-2}\right)$, and $S_{i}$ is the area of the $i$ th subarea $\left(\mathrm{m}^{2}\right)$. Note that the form and parameters are slightly different from the original one proposed by the USEPA; the latter by the USEPA aimed to estimate erosion in an annual time scale with multiple surface disturbances like adding or removing materials from the pile. We focus on single-event scenarios (only one disturbance or one strong wind activity) to obtain a direct comparison between elevated and flat surfaces, because industrial or construction piles normally have a short lifetime, and because different approaching wind speeds may have different levels of influence on wind erosion acceleration effect, thereby scattering the amplification factor. However, amplification factors for different wind speed scenarios are given in the end, together with an empirical equation that determines a factor considering multiple wind conditions, which can be used for a long-term estimation.

The emission potential for a dry surface based on wind tunnel experiment results is estimated using equation 2 :

$P=58\left(u^{*}-u_{t}^{*}\right)^{2}+25\left(u^{*}-u_{t}^{*}\right)$ for $u^{*}>u_{t}^{*}$, otherwise $P=0$,

where $u_{t}^{*}$ is the threshold friction velocity $\left(\mathrm{m} \mathrm{s}^{-1}\right)$, and $u^{*}$ is the friction wind velocity over the pile surface. $u^{*}$ can be estimated by using equation 3 :

$u^{*}=0.1 u$,

where $u_{s}$ is the wind speed at $25 \mathrm{~cm}$ above the pile's surface. $u^{*}$ for a flat surface is estimated by using equation 4 :

$u^{*}=0.053 u$,

where $u_{r}$ is the reference wind speed measured at $10 \mathrm{~m}$ height. Equations 3 and 4 assume a typical roughness height $\left(z_{0}\right)$ of
$0.005 \mathrm{~m}$ for open terrain condition. It is the different $u^{*}$ values over an elevated pile and a flat surface that lead to changes of erosion potential estimation, so the core procedure is to determine $u^{*}$ at $i$ th subarea of the pile surface. Note that the peak wind speed that is larger than the mean value during a wind event from the anemometer should be used to represent $u$, because $P$ is estimated from the fastest mile of wind (the wind speed that the wind passed by $1.6 \mathrm{~km}[1 \mathrm{mi}]$ in the least amount of time, as defined by the USEPA).

The mean particle or aggregate size is a decisive factor to wind erosion through its impact on $u_{t}^{*}$. By fitting a group of studies from decades ago to recent time (Bagnold 1937; Chepil 1945; Fletcher 1976a, 1976b; Greeley et al. 2003; Mazurak et al. 1953; Shao and Klose 2016; Shao and Lu 2000), $u_{t}^{*}$ can be estimated with a curve that has a valley around $70 \mu \mathrm{m}$ using equation 5 :

$u_{t}^{*}=0.29 \sqrt{6.90 d+\frac{0.034}{d}}$,

where $d$ is soil mean particle size ( $\mathrm{mm})$.

If we consider coal ash as a representative granular material, we can use an $u_{t}^{*}$ value of $0.35 \mathrm{~m} \mathrm{~s}^{-1}$ as recommended by the USEPA (Badr and Harion 2005, 2007; Toraño et al. 2007; Turpin and Harion 2009, 2010), corresponding to a loose material with mean particle size of $0.19 \mathrm{~mm}$ according to equation 5. Other $u_{t}^{*}$ or soil material conditions could also be tested, but the final pattern of the amplification factor might be similar since the erosion rates of the pile and flat surface change with $u_{t}^{*}$ in the same way as defined in equation 2 .

When $u_{r}$ is given, only $u_{s}$ and $S$ are unknown. The USEPA EF based on wind tunnel experiments was found rough in dividing surface subareas; therefore, we use the following CFD simulation to acquire $u_{s}$ and $S$ in a finer resolution.

The total erosion rate of a pile and that of a flat surface with the same floor area are compared to obtain the amplification factor. If the erosion rate of a flat surface with the same material as the pile under the same wind activity or during the same wind event is known, this factor can then be multiplied to estimate wind erosion of the pile. The wind erosion potential of many soils are experientially known (e.g., the wind erodibility group and indexes from the USDA Natural Resources Conservation Service [NRCS]), or they can be estimated from wind erosion 
models, such as the Wind Erosion Prediction System (WEPS) (Wagner 2013). Therefore, the proposed factors can be easily used at natural, agricultural, construction, and industrial sites.

Numerical Simulation. A conical pile model measuring $6 \mathrm{~m}$ in height and $7.2 \mathrm{~m}$ in bottom diameter was built based on field surveys undertaken at several construction sites (figure 1). The toe slope was about $39^{\circ}$, which is slightly larger than the natural repose angle of certain fine and dry materials (usually ranging from $32^{\circ}$ to $37^{\circ}$ ), because the piles at these construction sites may have a high water content inside, or consist of various aggregate groups and have strong inner cohesion to support a steep slope.

The entire simulation model was then scaled to build a group of six models containing other piles measuring $1,1.7,3,9$, and $12 \mathrm{~m}$ in height. The value of $1.7 \mathrm{~m}$ was used instead of $1.5 \mathrm{~m}$ (the latter is a quarter of the initial model) because the height of 1.7 $\mathrm{m}$ was found to be close to the height of piles in many slag areas in northwest China when dumped by an $8 \mathrm{~m}^{3}$ truck, which is most often used.

Many studies have demonstrated that the strength of a wind regime is proportional to the inlet wind speed for the turbulent erosive wind, which means the distribution of normalized wind speeds $\left(u_{s} / u_{r}\right)$ over different subareas remains the same over the pile under various inlet wind conditions (Badr and Harion 2007; Turpin and Harion 2009). This does not mean that the erosions over subareas remain the same under different wind conditions, because $u_{t}^{*}$ is fixed but the $u^{*}$ value over each subarea changes with reference wind speed. Therefore, the simulations were conducted using only one wind speed with $u=10 \mathrm{~m} \mathrm{~s}^{-1}$ at a height of $10 \mathrm{~m}$; then the distribution of $u / u_{r}$ was exported and other reference wind speed values were substituted to obtain the corresponding pile surface wind flow pattern. For each pile height condition, the $u_{s} / u$ range (interval of 0.1) and its corresponding area at a normal distance $25 \mathrm{~cm}$ above the pile surface were recorded. Results were integrated into $E F$ formulas to calculate dust emission rates for different $u$ conditions from 8 to 16 $\mathrm{m} \mathrm{s}^{-1}$ at an interval of $2 \mathrm{~m} \mathrm{~s}^{-1}$. The range of wind speeds considered was based on rough statistics of three-year (2010 to 2012) daily maximum wind speeds obtained from 824 Chinese meteorological stations. The lower

\section{Figure 1}

(a) A single conical pile at a construction site and (b) the computational fluid dynamics (CFD) model built with numerical meshes. The mesh size is finer close to the pile model and coarser far away.

(a)

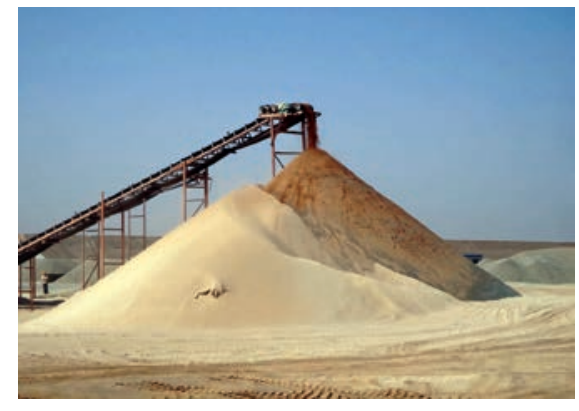

limit of $8 \mathrm{~m} \mathrm{~s}^{-1}$ was higher than the threshold wind speed of about $6 \mathrm{~m} \mathrm{~s}^{-1}$ at an observation height of $10 \mathrm{~m}$, while the upper limit of 16 $\mathrm{m} \mathrm{s}^{-1}$ covered $99.5 \%$ of all the measured data and $98.8 \%$ of erosive winds. Therefore, it was determined that this range should cover most of the wind erosion activity for a majority of the stations. Furthermore, the results showed that adding higher winds did not significantly change the final amplification factor, which reduced slowly at high wind speeds.

The commercial CFD software ANSYS Fluent 15.0 (ANSYS, Inc., Pittsburgh, Pennsylvania) was employed to simulate wind flow over various piles. For all the pile height and wind speed scenarios, the Reynolds number was calculated to be larger than $5.4 \times$ $10^{5}$, indicating turbulent flow conditions; thus, turbulent model simulations were performed. The shear-stress transport $\mathrm{k}-\omega$ turbulence model was selected to provide closure of Reynolds-averaged Navier-Stokes equations. The SIMPLEC algorithm was used to solve pressure-velocity coupling (the pressure interpolation scheme was PREssure Staggering Option [PRESTO!]). The second-order discretization schemes were used for convection and the viscous terms of the governing equations. Simulations were performed in steady-state, so the results represented mean conditions. Gambit software was used to build 3D geometry and a numerical grid.

Structured hexahedral grids with boundary layers, which provide increasing sizes for the first four layers of grids in the upstream, downstream, and upper regions, were generated, in addition to unstructured tetrahedral grids near the pile. Grid-sensitivity analysis was performed to determine the grid size and to ensure that further refining of the grid would lead to no noticeable change in the flow field. The total number of cells in the (b)

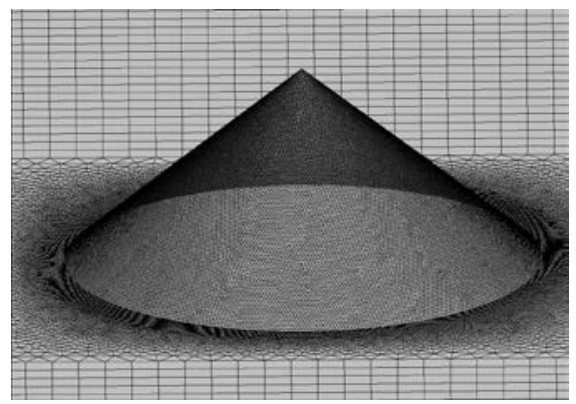

model was $7.8 \times 10^{5}$. The upstream boundary distance and the downstream distance were 5 and 26 times that of the pile model height, respectively, to guarantee full development of the flow field.

Velocity-inlet and pressure-outlet boundary conditions were applied to the inlet and exit, respectively, using calculated kinetic energy and the specific dissipation rate. The pile and surrounding surfaces were regarded as smooth solid walls with a roughness height of $0.005 \mathrm{~m}$. Symmetry boundary conditions were used for the lateral and upper sides.

The logarithmic inlet wind profile over a neutral atmospheric boundary layer condition was given by using equation 6 :

$u_{z}=u^{*} \div k \ln \left(z \div z_{0}\right)$,

where $u_{z}$ is the wind speed value at height $z(\mathrm{~m})$, and $k=0.4$ is the von Karman coefficient. Since we already knew the reference speed at $10 \mathrm{~m}$ height, $u^{*}$ can be determined using equation 6 and then the wind profile is obtained.

The turbulent kinetic energy (TKE), $k$, and the specific dissipation rate, $\omega$, were estimated from the relationships of equations 7 and 8:

$k=1.5\left(u_{\text {avg }} I\right)^{2}$, and

$\omega=k^{0.5} \div C_{\mu}^{0.25} \div \mathbf{l}$,

where $u_{a v g}$ is the mean flow velocity, $I$ is the turbulence intensity, $r$ is the turbulence length scale that is 0.07 times the pile height, and $C_{\mu}$ is an empirical constant with a value of 0.09 . The turbulence intensity, $I$, is estimated by using equation 9 :

$I=0.16 R_{e}^{-1 / 8}$. 
$R_{e}$ is estimated from equation 10 :

$R_{e}=\rho v d \div \mu$,

where $d$ is the characteristic length in the model (pile height in this case); $\rho, v$, and $\mu$ are the density, speed, and viscosity coefficients of air, respectively.

Details of the turbulent model parameters, grid-sensitivity analyses involved, mesh technique, and validation of the model can be found in our previous work and many other similar studies in the literature (Liu et al. 2011).

Validation Using Structure-from-Motion Method. Monitoring wind erosion in the field has a high logistical cost and is low in data accuracy because the erosion particle amount captured in a small sand sampler needs to be extrapolated to a large area. In some indoor tests, a whole weight change of the tested soil sample or model may be detectable; however, samples or models are usually limited in size, and variations in different parts of the erosion body cannot be easily monitored. In this study the built amplification factors are verified by high-resolution structure-from-motion (SfM) photogrammetry on two experimental surfaces with different heights.

The SfM uses photogrammetric methods and computer visualization techniques to create high-resolution digital elevation models (DEMs) and a 3D structure of the target using extensive photosets obtained with a consumer-grade camera (Westoby et al. 2012). We use SfM to measure wind erosion over two surfaces with different heights. This method will overcome shortages of some traditional wind erosion measurement methods (e.g., the low precision of survey pole, the low representativeness of sand sampler, and the complex operation of topographic survey).

SfM can be used in all areas of research related to landform or terrain analysis. Although the powerful SfM method has been applied to a wide range of geoscience research, such as gully water erosion, ice surface research, and landform evolution (Cook 2017; James and Robson 2012; Nouwakpo et al. 2016; Prosdocimi et al. 2017; Smith et al. 2016; Stöcker et al. 2015), this is the first time it is used in the wind erosion field to our knowledge. Neither the numerical simulations in the previous section nor the field measurements in this section could consider a wide range of pile parameters, and we want to check if the proposed factor can reflect the general trend of the influence of pile heights on wind erosion instead of specific erosion values.

A square plot $\left(4 \mathrm{~m}^{2}\right)$ and a round plot $(r=1 \mathrm{~m})$ were built and filled with sand at an experimental site of the Dunhuang Gobi Research Station, within the Northwest Institute of Eco-Environment and Resources, Chinese Academy of Sciences, Dunhuang City, in northwest China (figure 2). The square plot represented a flat erosion surface; however, its center area was about $10 \mathrm{~cm}$ higher than the side boundaries so that wind initiated particles could not be blocked inside the plot during the erosion process. The round plot represented a pile with a height of 37 $\mathrm{cm}$ in the center. At least three markers with determined locations (local coordinates) were mounted as ground-control points (GCPs) on the boundaries of the plots for georeferencing and data processing procedures later.

The station is located in an extremely arid region with multiyear average precipitation of only about $45 \mathrm{~mm}$, so water erosion would not possibly disturb the observation. This was assured as no significant rainfall event occurred during the experimental period and no splash pit or gully was formed over the pile surfaces. Animals were kept out of the station. As a result, surface modification of the plots was purely from natural wind erosion.

The survey of wind erosion using the SfM method began after the plots had been established and continued once in a while if significant surface change (erosive activity) happened. In each survey, about 80 digital pictures were taken covering each side and top of each plot, and at least three of these pictures showed each of the surface points on the plots. The commercial Agisoft Photoscan software (Agisoft LLC, St. Petersburg, Russia) was employed to extract key points, generate point clouds, match GCP locations, build a mesh, and export georeferenced DEMs. As each target was relatively small and pictures were easy to take, results with low transformation residuals (usually under millimeter level) could be obtained with high confidence.

After the DEMs of two phases were obtained, the change in elevation at each point could be processed within a geographic information system (GIS) working environment to determine the change in volume. By multiplying the volume change with the density of sand $\left(1,600 \mathrm{~kg} \mathrm{~m}^{-3}\right)$, the erosion amount and rate of the two surfaces with different heights within a same time period were acquired.

\section{Results and Discussion}

Computational Fluid Dynamics-Simulated Wind Distribution over Piles. The USEPA estimation method divides the pile surface into four subareas bounded by 0.2, 0.6, and $0.9 u_{s} / u_{r}$ levels (figure 3a). However, the CFD simulation allows for much finer results because detailed surface wind movement is calculated (figure $3 \mathrm{~b}$ ). The flow accelerates along the upwind surface and is separated into two sides, while a negative wind speed region with an inverse flow is formed at the center. The simulated flow pattern is in agreement with the results of previous studies on pile and dune surfaces (Badr and Harion 2005; Cong et al. 2012; Ferreira et al. 2011; Liu et al. 2011; Toraño et al. 2007; Turpin and Harion 2009).

The flow speed at the top of the pile increases with pile height, while the toe zone intensity is much smaller, as can be seen in examples of 6 and $12 \mathrm{~m}$ high piles (figure $3 \mathrm{c}$ and $3 d$ ). As a result, the higher pile surface is divided into a large number of subareas and strength levels. The area of each subarea with a $0.1 u_{s} / u_{r}$ interval at $25 \mathrm{~cm}$ above the pile is integrated, and the area ratios for all the levels are tabulated (table 1).

The higher the pile, the larger surface subareas with stronger wind levels it has. The 1 $\mathrm{m}$ high pile has no surface $u_{s} / u_{r}$ ratio larger than 1 , while the $12 \mathrm{~m}$ pile has a spot where wind speed at $25 \mathrm{~cm}$ above the surface is $60 \%$ higher than the reference wind speed at $10 \mathrm{~m}$ height. This changing trend of pile surface wind strength with height indicates the feasibility of building a relationship between pile height and wind erosion potential. It can be expected that a higher pile would lead to larger erosion quantity as well as amplification factor compared to a lower pile.

Pile Erosion Rate. After obtaining the surface wind speed distribution, equations 2 through 4 are used to estimate the erosion rate $(P$ values in equation 2$)$ of each surface subarea of the pile and the corresponding flat surface, which are listed in table 2 . The erosion rate increases significantly, in line with wind speed as defined in equation 2. The surface area of the pile with known bottom radius and height can be easily calculated, 


\section{Figure 2}

Wind erosion experimental plots constructed for structure-from-motion (SfM) validation. (a) The round plot was designed to represent a pile; sand was added at top in the center. (b) The square plot was low in height with its central area higher than its edges.

(a)

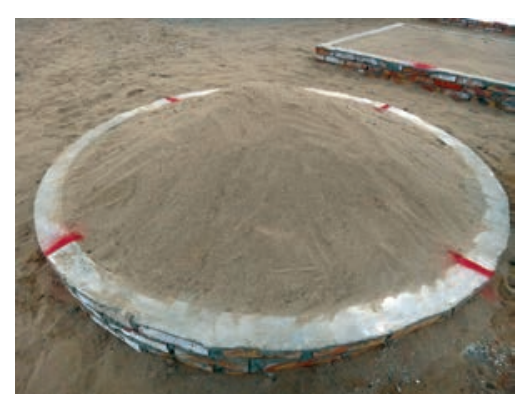

(b)

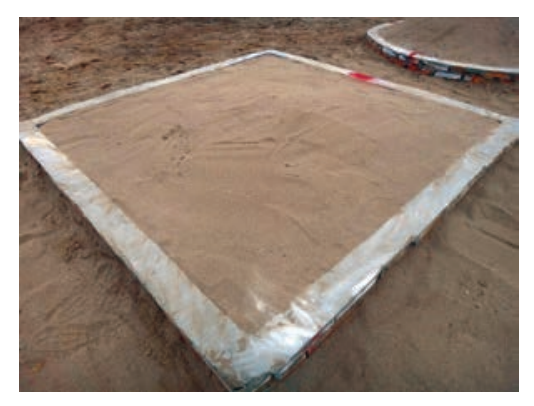

\section{Figure 3}

(a) Wind distribution results over piles from US Environmental Protection Agency (USEPA) estimation (USEPA 1995); the letters "a" and "b" following 0.2 represent two parts that have the same wind speed level. (b) Vector map showing wind acceleration on the upwind side and reverse flow on the downwind side, where the vector scale represents the strength of the reference wind speed. (c) and (d) are contour maps showing distributions of different surface wind strength levels over 6 and $12 \mathrm{~m}$ high piles under the same reference wind condition.

(a)

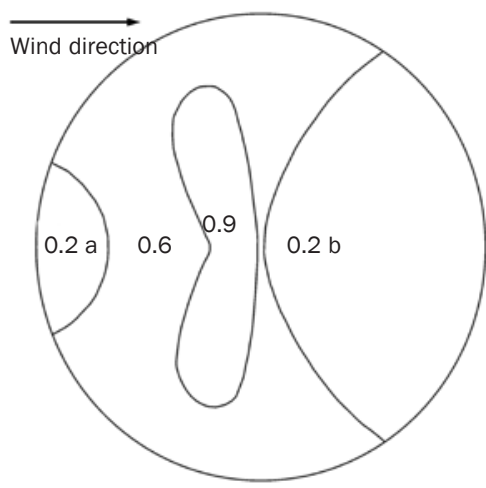

(c)

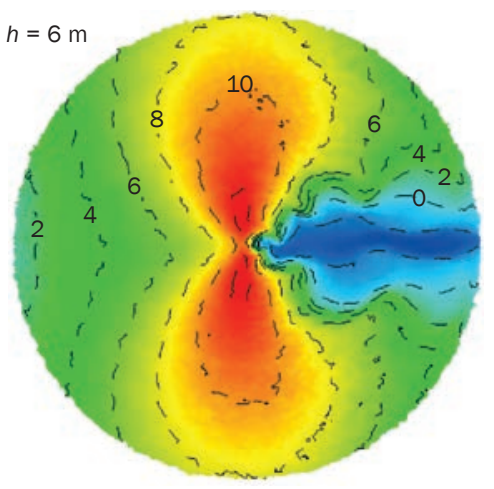

(b)

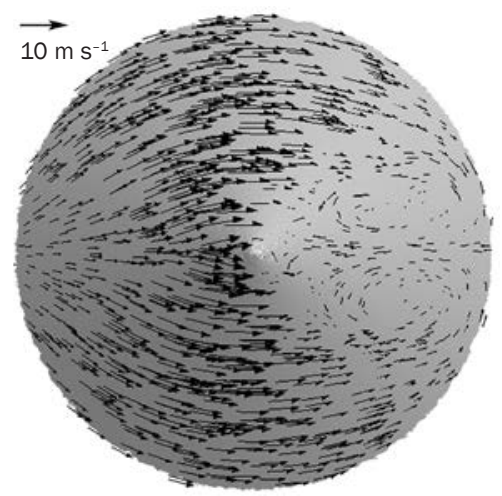

(d)

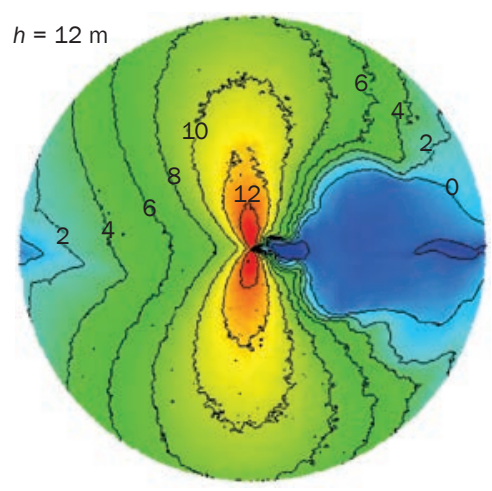

as the subarea ratios are given in table 1. Equation 1 is used to obtain the final total erosion rate of each pile height under different wind conditions. This is achieved by multiplying the corresponding cells in table
Amplification Factors in Pile Wind Erosion. Similar procedures to those in the "Computational Fluid Dynamics-Simulated Wind Distribution over Piles" and "Pile Erosion Rate" sections have been used to evaluate wind erosion from different shapes and configurations of piles, but those values were suitable only for the typical piles used (Toraño et al. 2007; Turpin and Harion 2009, 2010). The ratios of the erosion rates of a pile to those of a flat surface with the same floor area are regarded here as the amplification factors $\left(E_{\text {amp }}\right)$, and their values are listed for the six pile height and five wind speed conditions (table 3). In this way, the factors can be applied to consider wind erosion of piles with different heights or sizes under various wind conditions.

For each pile height, the amplification factors decrease sharply with wind speed starting at $8 \mathrm{~m} \mathrm{~s}^{-1}$ because the erosion rate from a flat surface (the denominator) is small with low wind speed. The factors tend to be gentle and stable at higher wind speeds, although the actual erosion rate is much higher under high wind speed conditions as shown in table 2. The changing pattern in relation to pile height is fitted to power equations as:

$$
E_{a m p}=a \times v^{-b},
$$

where wind speed $(v)$ is the independent variable, $a$ and $b$ are constant coefficients, and $R^{2}>0.88$. Therefore, it is possible to estimate $E_{\text {amp }}$ of a pile height under various other wind strength conditions.

Under each wind strength condition, the factor increases logarithmically with the height of the pile as:

$$
E_{\text {amp }}=c \times \ln (h)+d,
$$

where pile height $(h)$ is the independent variable, and $c$ and $d$ are constant coefficients. It clearly shows that the higher the pile, the greater amount of wind it is subjected to, because wind speed increases logarithmically with heights; as a result, the top section of a pile suffers more severe wind erosion. Regressions all have high confidence levels, with $R^{2}>0.98$, which means the column-fitted equation can be used to estimate $E_{\text {amp }}$ for other pile heights. However, confidence would reduce if the equations are extrapolated to heights and wind speeds outside of the tested ranges. 
Table 1

Area ratios of different subareas subjected to different levels of wind strengths over piles.

\begin{tabular}{lllllll}
\hline & \multicolumn{6}{l}{ Pile heights $(\mathbf{m})$} \\
\cline { 2 - 6 } $\mathbf{u}_{\mathbf{s}} / \mathbf{u}_{\boldsymbol{r}}$ level & $\mathbf{1 . 0}$ & $\mathbf{1 . 7}$ & $\mathbf{3 . 0}$ & $\mathbf{6 . 0}$ & $\mathbf{9 . 0}$ & $\mathbf{1 2 . 0}$ \\
\hline 0.0 to 0.1 & 0.08 & 0.09 & 0.10 & 0.12 & 0.18 & 0.17 \\
0.1 to 0.2 & 0.01 & 0.02 & 0.02 & 0.03 & 0.03 & 0.04 \\
0.2 to 0.3 & 0.01 & 0.04 & 0.05 & 0.06 & 0.05 & 0.05 \\
0.3 to 0.4 & 0.04 & 0.07 & 0.08 & 0.07 & 0.06 & 0.06 \\
0.4 to 0.5 & 0.09 & 0.10 & 0.09 & 0.08 & 0.07 & 0.07 \\
0.5 to 0.6 & 0.14 & 0.12 & 0.10 & 0.09 & 0.08 & 0.08 \\
0.6 to 0.7 & 0.22 & 0.16 & 0.13 & 0.10 & 0.08 & 0.08 \\
0.7 to 0.8 & 0.25 & 0.19 & 0.16 & 0.12 & 0.09 & 0.09 \\
0.8 to 0.9 & 0.15 & 0.15 & 0.13 & 0.13 & 0.12 & 0.11 \\
0.9 to 1.0 & 0.00 & 0.08 & 0.09 & 0.10 & 0.10 & 0.10 \\
1.0 to 1.1 & 0.00 & 0.00 & 0.05 & 0.07 & 0.06 & 0.07 \\
1.1 to 1.2 & 0.00 & 0.00 & 0.00 & 0.04 & 0.04 & 0.04 \\
1.2 to 1.3 & 0.00 & 0.00 & 0.00 & 0.01 & 0.02 & 0.02 \\
1.3 to 1.4 & 0.00 & 0.00 & 0.00 & 0.00 & 0.01 & 0.01 \\
1.4 to 1.5 & 0.00 & 0.00 & 0.00 & 0.00 & 0.0038 & 0.0046 \\
1.5 to 1.6 & 0.00 & 0.00 & 0.00 & 0.00 & 0.001 & 0.0018 \\
1.6 to 1.7 & 0.00 & 0.00 & 0.00 & 0.00 & 0.00 & 0.00002 \\
Total & 1.00 & 1.00 & 1.00 & 1.00 & 1.00 & 1.00 \\
& & & & & &
\end{tabular}

Table 2

Wind erosion rates $\left(\mathrm{g} \mathrm{m}^{-2}\right)$ over pile surface with multiple subarea wind strength levels under different wind speed conditions.

\begin{tabular}{|c|c|c|c|c|c|}
\hline \multirow{2}{*}{$\begin{array}{l}\text { Erosion rate } \\
u_{s} / u_{r} \text { level }\end{array}$} & \multicolumn{5}{|c|}{ Wind speed $\left(\mathrm{m} \mathrm{s}^{-1}\right)$} \\
\hline & 8 & 10 & 12 & 14 & 16 \\
\hline 0.0 to 0.1 & 0.00 & 0.00 & 0.00 & 0.00 & 0.00 \\
\hline 0.1 to 0.2 & 0.00 & 0.00 & 0.00 & 0.00 & 0.00 \\
\hline 0.2 to 0.3 & 0.00 & 0.00 & 0.26 & 2.03 & 4.23 \\
\hline 0.3 to 0.4 & 0.00 & 1.40 & 4.23 & 7.81 & 12.13 \\
\hline 0.4 to 0.5 & 1.40 & 5.06 & 9.88 & 15.86 & 23.00 \\
\hline 0.5 to 0.6 & 4.23 & 9.88 & 17.19 & 26.18 & 36.83 \\
\hline 0.6 to 0.7 & 7.81 & 15.86 & 26.18 & 38.77 & 53.64 \\
\hline 0.7 to 0.8 & 12.13 & 23.00 & 36.83 & 53.64 & 73.41 \\
\hline 0.8 to 0.9 & 17.19 & 31.30 & 49.16 & 70.78 & 96.16 \\
\hline 0.9 to 1.0 & 23.00 & 40.76 & 63.16 & 90.20 & 121.88 \\
\hline 1.0 to 1.1 & 29.54 & 51.38 & 78.82 & 111.88 & 150.56 \\
\hline 1.1 to 1.2 & 36.83 & 63.16 & 96.16 & 135.85 & 182.21 \\
\hline 1.2 to 1.3 & 44.86 & 76.10 & 115.17 & 162.08 & 216.84 \\
\hline 1.3 to 1.4 & 53.64 & 90.20 & 135.85 & 190.59 & 254.43 \\
\hline 1.4 to 1.5 & 63.16 & 105.46 & 158.20 & 221.38 & 295.00 \\
\hline 1.5 to 1.6 & 73.41 & 121.88 & 182.21 & 254.43 & 338.53 \\
\hline 1.6 to 1.7 & 84.42 & 139.46 & 207.90 & 289.76 & 385.03 \\
\hline Flat surface & 2.17 & 6.38 & 11.89 & 18.71 & 26.83 \\
\hline
\end{tabular}

A factor with a value close to the speed of the most erosive wind can be selected if the erosion in a short period or after a surface disturbance is wanted. The process should be repeated to consider the total erosion of a pile during its lifetime. Using an overall factor is also useful if it is necessary to know the amount of erosion over a long period with different erosive wind events but detailed wind data are not available. In such a case, erosion rate-weighted average values are recommended (these tend to be very close to the $12 \mathrm{~m} \mathrm{~s}^{-1}$ equation), as in equation 13 :

$E_{\text {amp }}=0.38 \ln (h)+2.75$.

The coefficients in equation 13 may change slightly if other wind strength levels outside of the tested range are included, but they should be generally acceptable because equation 13 covers the majority of erosive wind conditions as mentioned in the "Numerical Simulation" section, and because wind with peak speed smaller than $8 \mathrm{~m} \mathrm{~s}^{-1}$ has no significance in wind erosion while the wind stronger than $16 \mathrm{~m} \mathrm{~s}^{-1}$ has weak influence on the regression curve.

Many soils or granular materials have their own estimated wind erosion module or wind erodibility under a flat surface conditionfor example, the values listed in the national soil survey handbook of USDA NRCS. With the proposed equation 13, a general erosion amount from a pile can now be estimated. If we know the wind erodibility of a homogeneous fine sandy loam soil is about $21.25 \mathrm{~kg}$ $\mathrm{m}^{-2} \mathrm{y}^{-1}$, and a conical pile with $6 \mathrm{~m}$ height and $162.86 \mathrm{~m}^{2}$ base area consists of the same soil has a 3.44 times of erosion rate compared to a flat surface according to equation 13 , we can then estimate that this pile, if its lifetime is over one year, may lose $72.89 \mathrm{~kg} \mathrm{~m}^{-2}$ soil in a year, and that the total erosion amount is about $11.87 \mathrm{t}$

The procedures used to obtain the values in tables 1 through 3 can be adopted and used not only for different piles, but also any uneven erosive surfaces like dunes, hills, pits, or gullies. The capability of the current wind erosion models that simulate flat surface (WEPS, for example) can be improved to deal with 3D terrains, and their application range can be broadened if more results from different uneven surfaces become available. As a result, the current work will broadly benefit wind erosion estimation and model developing research.

Validation of Structure-from-Motion Method. The SfM method provides an opportunity to observe the total erosion amount and rate over a surface without redundant disturbance or interpolation from a point observation to surface estimation. The system error of the measurements are low, and the loss of materials from the plots are purely from wind erosion. This is a major advantage of SfM method compared to the traditional 
Table 3

Amplification factors of piles with different heights under various wind speed conditions.

\begin{tabular}{|c|c|c|c|c|c|c|c|c|}
\hline \multirow[b]{2}{*}{$E_{\text {amp }}$} & \multicolumn{5}{|c|}{ Wind speed $\left(\mathrm{m} \mathrm{s}^{-1}\right)$} & \multicolumn{3}{|c|}{$E_{a m p}=a \times v^{-b}$} \\
\hline & 8 & 10 & 12 & 14 & 16 & a & b & $R^{2}$ \\
\hline \multicolumn{9}{|l|}{ Height (m) } \\
\hline 1.0 & 4.78 & 3.20 & 2.80 & 2.62 & 2.52 & 27.62 & 0.89 & 0.88 \\
\hline 1.7 & 5.11 & 3.35 & 2.91 & 2.72 & 2.61 & 32.37 & 0.94 & 0.88 \\
\hline 3.0 & 5.57 & 3.59 & 3.09 & 2.87 & 2.74 & 38.9 & 0.99 & 0.89 \\
\hline 6.0 & 6.42 & 4.04 & 3.44 & 3.17 & 3.02 & 51.05 & 1.05 & 0.89 \\
\hline 9.0 & 6.88 & 4.26 & 3.60 & 3.30 & 3.13 & 60.23 & 1.10 & 0.89 \\
\hline 12.0 & 7.16 & 4.41 & 3.72 & 3.41 & 3.24 & 70.33 & 1.15 & 0.89 \\
\hline \multicolumn{9}{|c|}{$E_{\text {amp }}=c \times \ln (h)+d$} \\
\hline$c$ & 0.99 & 0.51 & 0.39 & 0.33 & 0.30 & & & \\
\hline$d$ & 4.65 & 3.12 & 2.74 & 2.57 & 2.47 & & & \\
\hline$R^{2}$ & 0.99 & 0.99 & 0.98 & 0.98 & 0.98 & & & \\
\hline
\end{tabular}

wind erosion observation, such as sand flux sampling. We obtained three survey results for both plots in December of 2015 and in April and September of 2016. The generated DEMs contained information pertaining to the highest points and the total volume of the plot at each survey time (figure 4).

The proposed equation 13 is then used to calculate $E_{\text {amp }}$ at each survey time (because the monitoring periods contained multiple wind activities and a long-term estimation was required), and the adjacent two values are averaged to obtain an $E_{a m p}$ for the erosive period. The ratios of $E_{a m p}$ from the round and square plots are then obtained. In addition, the erosion amounts and rates for each plot during the two periods are processed and the erosion ratio is obtained. A comparison of the two methods show that the estimation differences are only $2.5 \%$ and $1.5 \%$ for the two periods (table 4).

\section{Figure 4}

Digital elevation models (DEMs) of the two plots generated using structure-from-motion (SfM) method in Survey 1 in December of 2015.
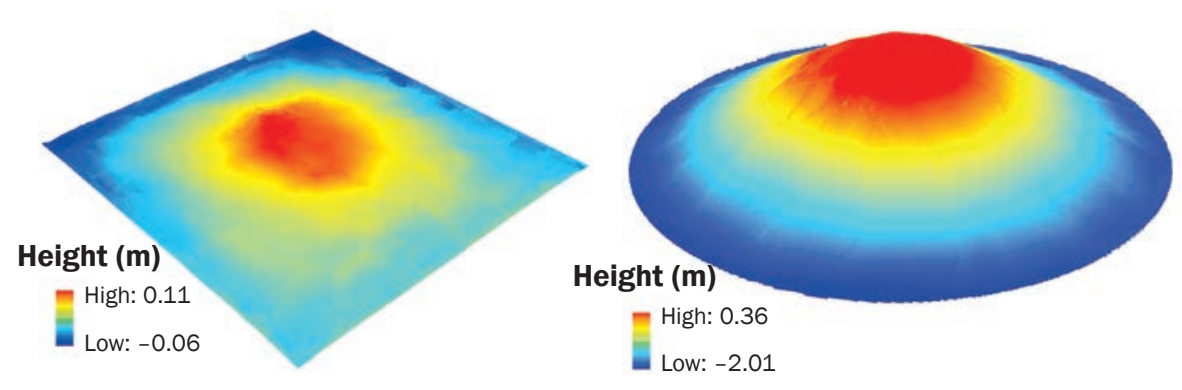

During the monitoring periods, we recorded multiple wind activities at the test area. The good agreement between the estimated erosion rates and the observed ones shows the effectiveness of the proposed factors in table 3. However, the observation of wind erosion took about nine months, and the sands were only disturbed once they were filled into the plots. As a result, the surface coarsening effect could be significant and the measured erosion rates might be lower compared to natural dry sands, resulting in inconstancy of the verification results. The verification performance may also vary for other pile shape, soil type, and wind conditions.

The SfM method can be applied to a wide range of wind erosion or wind and water complex erosion over flat or elevated bare surfaces. A larger area can also be considered with the help of additional equipment such as unmanned aerial vehicles. For example, the precise observation of soil loss over hills or gullies on the Loess Plateau can be performed so that detailed soil and water conservation measures can be taken.

\section{Summary and Conclusions}

In this study, amplification factors were proposed for estimating wind erosion of a single conical pile by considering different pile heights and wind speeds. The principle of the USEPA wind erosion rate estimation for piles was improved using a CFD simulation to consider a finer pile surface wind distribution, and the rates from piles were compared to corresponding ones from flat surfaces to obtain $E_{\text {amp }}$ factors. By multiplying the factors of a pile with a certain height under a given wind speed condition (or over a long wind period) with the known erosion rate over a type of flat soil surface (or from other wind erosion models), the total wind erosion from

Table 4

Estimated amplification factors $\left(E_{a m p}\right)$ during different monitoring periods and observed ones using Structure-from-Motion (SfM) method.

\begin{tabular}{|c|c|c|c|c|c|c|c|c|c|}
\hline \multirow[b]{2}{*}{ Survey } & \multicolumn{2}{|c|}{ Height (m) } & \multicolumn{3}{|c|}{$\begin{array}{l}\text { Estimated } E_{\text {amp }} \\
\text { between two periods }\end{array}$} & \multicolumn{3}{|c|}{ SfM observed erosion $\left(\mathrm{kg} \mathrm{m}^{-2}\right)$} & \multirow{2}{*}{$\begin{array}{l}\text { Ratio } \\
\text { difference (\%) }\end{array}$} \\
\hline & Pile & Flat & Pile & Flat & Ratio & Pile & Flat & Ratio & \\
\hline 1 & & & 2.33 & 1.92 & 1.21 & 18.86 & 15.94 & 1.18 & 2.5 \\
\hline 2 & 0.30 & 0.12 & & & & & & & \\
\hline
\end{tabular}


a pile can be estimated. For example, the erosion rate for a $6 \mathrm{~m}$ pile can be estimated as being 3.44 times that of a flat surface with the same floor area.

In addition, in this paper formulas for other wind speeds or pile heights were fitted with relatively high confidence (table 3 ). Equation 13 can be used to give a general estimation of wind erosion acceleration of piles with different heights, as it considers most normal erosive wind speed conditions.

The effectiveness of the factor was verified using SfM photogrammetry, which extracted the detailed volume change of a whole surface at a millimeter-level resolution. Two outdoor experimental plots with different heights were built, and their volume changes were recorded to calculate the erosion amounts and differences. The noncontact measurements of SfM method assured that the loss of surface materials from the two plots were only caused by wind erosion. The results of two validation periods from three surveys agreed well with the proposed $E_{a m p}$, which indicates that the proposed factor and estimation equation properly reflect the influence of pile height on pile wind erosion. This study is probably the first application of the SfM method in wind erosion research.

The proposed factors in table 3 can be applied to other wind erosion indexes or models. The procedures presented in this paper can also be extended to consider amplification or reduction effects of dunes, hills, pits, and gullies with different shapes or configurations in relation to wind erosion, so that the reliability of wind erosion estimation over complex surfaces can be improved. In the future, amplification factors for piles or gullies with various shapes and configurations, as well as different loose materials, will be obtained. Also, more plots with different soils and multiple SfM monitoring in shorttime intervals can be performed to test any new amplification factors.

\section{Acknowledgements}

We would like to thank Sayjro Kossi Nouwakpo, researcher from the Natural Resources and Environment Sciences, University of Nevada-Reno in Reno, Nevada, for his help in SfM photogrammetry analysis. This study was supported by the National Science Fund of China (41501008), the China Postdoctoral Science Foundation (2014M550518), the Youth Innovation Promotion Association (2016373), and the "Light of West China" Program of the Chinese Academy of Sciences. Historical climate data were downloaded from the China Meteorological Data Sharing Service System.

\section{References}

Alfaro, S.C., and L. Gomes. 2001. Modeling mineral aerosol production by wind erosion: Emission intensities and aerosol size distributions in source areas. Journal of Geophysical Research: Atmospheres 106:18075-18084.

Badr, T., and J.L. Harion. 2005. Numerical modelling of flow over stockpiles: Implications on dust emissions. Atmospheric Environment 39:5576-5584.

Badr, T., and J.L. Harion. 2007. Effect of aggregate storage piles configuration on dust emissions. Atmospheric Environment 41:360-368.

Bagnold, R.A. 1937. The size-grading of sand by wind. Proceedings of the Royal Society of London A 163:0250-0264.

Bagnold, R.A. 1941. The Physics of Blown Sand and Desert Dunes. London: Dover.

Chepil, W.S. 1945. Dynamics of wind erosion: II. Initiation of soil movement. Soil Science 60:397-411.

Cong, X.C., S.L. Yang, S.Q. Cao, Z.L. Chen, M.X. Dai, and S.T. Peng. 2012. Effect of aggregate stockpile configuration and layout on dust emissions in an open yard. Applied Mathematical Modelling 36:5482-5491.

Cook, K.L. 2017. An evaluation of the effectiveness of lowcost UAVs and structure from motion for geomorphic change detection. Geomorphology 278:195-208.

Diego, I., A. Pelegry, S. Torno, J. Toraño, and M. Menendez. 2009. Simultaneous CFD evaluation of wind flow and dust emission in open storage piles. Applied Mathematical Modelling 33:3197-3207.

Dong, Z., H. Wang, X. Liu, F. Li, and A. Zhao. 2002. Velocity profile of a sand cloud blowing over a gravel surface. Geomorphology 45:277-289.

Farimani, A.B., A.D. Ferreira, and A.C.M. Sousa. 2011. Computational modeling of the wind erosion on a sinusoidal pile using a moving boundary method. Geomorphology 130:299-311.

Ferreira, A.D., A. Farimani, and A.C.M. Sousa. 2011. Numerical and experimental analysis of wind erosion on a sinusoidal pile. Environmental Fluid Mechanics 11:167-181.

Fletcher, B. 1976a. Erosion of dust by an air-flow. Journal of Physics D: Applied Physics 9:913.

Fletcher, B. 1976b. Incipient motion of granular-materials. Journal of Physics D: Applied Physics 9:2471-2478.

Furieri, B., J.M. Santos, S. Russeil, and J.-L. Harion. 2014. Aeolian erosion of storage piles yards: Contribution of the surrounding areas. Environmental Fluid Mechanics 14:51-67.

Greeley, R., M.R. Balme, J.D. Iversen, S. Metzger, R. Mickelson, J. Phoreman, and B. White. 2003. Martian dust devils: Laboratory simulations of particle threshold. Journal of Geophysical Research: Planets 108(5), doi:10.1029/2002JE001987.

Hagen, L.J. 2001. Validation of the Wind Erosion Prediction System (WEPS) Erosion Submodel on Small Cropland Fields. In Soil Erosion Research for the 21st Century, Proceedings, January 3-5, 2001, Honolulu, Hawaii, 479-482.
Jackson, D., N. Cruz-Avero, T. Smyth, and L. HernándezCalvento. 2013. 3D airflow modelling and dune migration patterns in an arid coastal dune field. Journal of Coastal Research 1301-1306.

James, M.R., and S. Robson. 2012. Straightforward reconstruction of $3 \mathrm{D}$ surfaces and topography with a camera: Accuracy and geoscience application. Journal of Geophysical Research: Earth Surface 117:1-17.

Liu, B., J. Qu, W. Zhang, and G. Qian. 2011. Numerical simulation of wind flow over transverse and pyramid dunes. Journal of Wind Engineering and Industrial Aerodynamics 99:879-888.

Mazurak, A.P., A.W. Zingg, and W.S. Chepil. 1953. Effect of 39 years of cropping practices on wind erodibility and related properties of an irrigated chestnut soil. Soil Science Society of America Proceedings 17:181-185.

Nouwakpo, S.K., M.A. Weltz, and K. McGwire. 2016. Assessing the performance of structure-frommotion photogrammetry and terrestrial LiDAR for reconstructing soil surface microtopography of naturally vegetated plots. Earth Surface Processes and Landforms 41:308-322.

Parsons, D.R., G.F.S. Wiggs, I.J. Walker, R.I. Ferguson, and B.G. Garvey. 2004. Numerical modelling of airflow over an idealised transverse dune. Environmental Modelling and Software 19:153-162.

Prosdocimi, M., M. Burguet, S. Di Prima, G. Sofia, E. Terol, J. Rodrigo Comino, A. Cerda, and P. Tarolli. 2017. Rainfall simulation and Structure-from-Motion photogrammetry for the analysis of soil water erosion in Mediterranean vineyards. The Science of the Total Environment 574:204-215.

Shao,Y.P., and M. Klose. 2016. A note on the stochastic nature of particle cohesive force and implications to threshold friction velocity for aerodynamic dust entrainment. Aeolian Research 22:123-125.

Shao, Y.P., and H. Lu. 2000. A simple expression for wind erosion threshold friction velocity. Journal of Geophysical Research: Atmosphere 105:22437-22443.

Smith, M.W., D.J. Quincey, T. Dixon, R.G. Bingham, J.L. Carrivick, T.D.L. Irvine-Fynn, and D.M. Rippin. 2016. Aerodynamic roughness of glacial ice surfaces derived from high-resolution topographic data. Journal of Geophysical Research: Earth Surface 121.

Smyth, T.A.G. 2016. A review of Computational Fluid Dynamics (CFD) airflow modelling over aeolian landforms. Aeolian Research 22:153-164.

Stöcker, C., A. Eltner, and P. Karrasch. 2015. Measuring gullies by synergetic application of UAV and close range photogrammetry: A case study from Andalusia, Spain. Catena 132:1-11.

Stunder, B.J.B., and S.P.S.Arya. 1988. Windbreak effectiveness for storage pile fugitive dust control: A wind-tunnel study. Journal of Air \& Waste Management Association 38:135-143. 
Sullivan, D.A., and H.A. Ajwa. 2011. Evaluation of wind erosion emissions factors for air quality modeling. Soil Science Society of America Journal 75:1285-1294.

Tatarko, J., S.J. van Donk, J.C. Ascough Ii, and D.G. Walker. 2016. Application of the WEPS and SWEEP models to non-agricultural disturbed lands. Heliyon doi:10.1016/j. heliyon.2016.e00215.

Toraño, J.A., R. Rodriguez, I. Diego, J.M. Rivas, and A. Pelegry. 2007. Influence of the pile shape on wind erosion CFD emission simulation. Applied Mathematical Modelling 31:2487-2502.

Toraño, J.A., S. Torno, I. Diego, M. Menendez, and M. Gent. 2009. Dust emission calculations in open storage piles protected by means of barriers, CFD and experimental tests. Environmental Fluid Mechanics 9:493-507.

Turpin, C., and J.L. Harion. 2009. Numerical modeling of flow structures over various flat-topped stockpiles height: Implications on dust emissions. Atmospheric Environment 43:5579-5587.

Turpin, C., and J.L. Harion. 2010. Effect of the topography of an industrial site on dust emissions from open storage yards. Environmental Fluid Mechanics 10:677-690.

USDA NRCS (Natural Resources Conservation Service). National Soil Survey Handbook, Title 430VI. Washington, DC: USDA Natural Resources Conservation Service. http://www.nrcs.usda.gov/wps/ portal/nrcs/detail/soils/ref/?cid=nrcs142p2_054242.

USEPA (US Environmental Protection Agency). 1995. Miscellaneous Sources, Industrial Wind Erosion. In Emissions Factors and AP 42, 5th edition, volume 1. Washington, DC: US Environmental Protection Agency.

Wagner, L.E. 2013. A history of wind erosion prediction models in the United States Department of Agriculture: The Wind Erosion Prediction System (WEPS). Aeolian Research 10:9-24.

Wakes, S. 2013. Three-dimensional Computational Fluid Dynamic experiments over a complex dune topography. Journal of Coastal Research 1337-1342.

Westoby, M.J., J. Brasington, N.F. Glasser, M.J. Hambrey, and J.M. Reynolds. 2012. Structure-from-Motion photogrammetry: A low-cost, effective tool for geoscience applications. Geomorphology 179:300-314.

Zhang, D., C. Narteau, O. Rozier, and S. Courrech du Pont. 2012. Morphology and dynamics of star dunes from numerical modelling. Nature Geoscience 5:463-467.

Zhang, J.-Q., C.-L. Zhang, C.-P. Chang, R.-D. Wang, and G. Liu. 2017. Comparison of wind erosion based on measurements and SWEEP simulation: A case study in Kangbao County, Hebei Province, China. Soil and Tillage Research 165:169-180. 